\title{
Kosovo Economic Trends and Fiscal Compliance
}

\author{
Phd@ Remzi Smajli \\ Professor, Faculty of Economics, "FAMA" College, Pristina
}

\begin{abstract}
In the last thirty years the world economy has followed different fenomene impact on national economies of countries and continents. During this period, the biggest impact that has had more influence in political terms, the world economy and financial markets was globalization.

After World War II, the United States has used its capital as energy to build a system that reflects the values and priorities of the West. Bretton Woods Agreement, the IMF, World Bank, United Nations, NATO and the G-7 were ultimately based institutions for global economic architecture. In this system, multinational corporations operated with some limitations, the development of national economies was based on the provision of free products as a condition for success in the world overall.

Developed and developing countries and their governments had limited roles as actor in the global economy Globalization caused an explosion in cross-border trade and innovation by opening new markets and caused significant economic increase, helped in reducing inflation, corporate transformation, leaving the poor, disease, dashing historical and ideological barriers. However, the phenomenon of globalization produced challenges for the world and the environment in which we live.

Globalization has created a world where financial markets and exchanges are linked more closely than ever but depending on geographic position, linking the states with international institutions, participating in globalization, depends on the impact of this phenomenon on the national economy. Kosovo as a new state with smaller proportions of GDP, import, export and limited participation in international institutions, global has been less affected by this phenomenon. However, being in the process of global involvement in these instances, Development of growing international trade and the presence of major international liaison with financial markets make our country Kosovo will be affected by the international crisis and globalization phenomena.
\end{abstract}

Keywords: Economy, Kosovo's economy, globalization, Fiscal Compliance.

\section{Economic growth}

Current data indicate that Kosovo as a whole has managed to remain partially affected by the ongoing crisis, which affected the global financial markets, followed by economic crisis mainly in developed countries in 2009, and it now has gripped several countries euro-zone mostly related to public debt. Economic trends in Kosovo in recent years Last year was characterized by a huge debt crisis that engulfed mainly euro-zone countries. Although to a limited extent, the effects of this crisis were reflected in Kosovo through the fall of exports of goods and services and foreign direct investment fall.

Given that the Kosovar diaspora is found mainly in Germany and Switzerland, as well as being based on actual data for the first half of 2015, the effects of this crisis is expected to be limited to the flow of remittances in Kosovo. These developments and current trends provide indications that economic growth for 2015 will be $3.5 \%$. Positive effects on economic growth this year is estimated to get adopted mainly private consumption and total investment. Import structure in Kosovo presents a clear picture of the level of total consumption.

The data import so far there has been a pronounced increase in the amount of imported consumer goods. More specifically, after the steep decline during the first two months of the year, in the coming months is recorded an increase of over $13 \%$ of the quantity of imported consumer goods. Although this increase can be supported by the establishment of workers' compensation revenue Kosovo working in Middle East countries, the full effect of raising the salaries of some categories of civil servants in the past year is estimated to have been considerable. At the same time, this has contributed to the growth of loans to households. Moreover, this increase can partly be supported by the slight decrease in the price of food, which may have contributed to the increase of consumption. An additional factor that has stimulated consumption in 2013 and during 2014, has been the distribution of funds reserved for workers from the privatization of SOEs, or $15 \%$ of the proceeds of the assets of privatized SOEs. As a result of these factors, the real growth of private consumption for 2015 foreseen to be $3.5 \%$. 
The current data show that the structure of imported goods is continuously showing a tendency to shift goods used as raw material for production as well as to goods for investment. This confirms the fact of the continued growth Effects of global risk in transition countries 524 of investment in Kosovo, which is expected to improve the level of substitution of imported goods with domestic products. Consequently, based on import data and its structure during the period January-September 2015 saw an increase of $16 \%$ in the quantity of imports of investment goods. Establishment of private investment has been mainly as a result of the continuous improvement of conditions for business development coupled with favorable tax policies. Also, to increase investment this year, significant impact has been the decline of prices of imports of construction goods, which comes as a result of lower metal prices. Therefore, based on these developments, at the end of 2015 total investments are forecast to grow by $11.0 \%$ in real rates.

Significant contribution to overall investment growth this year have been public investment. These investments primarily relate to important infrastructure projects which are expected to continue over the coming period. Economic growth in 2014 has slowed considerably decrease the export of goods. This decrease is mainly attributed to the fall of international prices of metals, which has resulted in the decline of exports of metals, these products which constitute about $60 \%$ of Kosovar export of goods. Although based on the latest data, the amount of exported goods has decreased by over $17 \%$, it is estimated that in addition to metals, the export of other products has increased significantly due to the low base of export growth of these products only managed to partially compensate the decline in export of metal. As a result, exports of goods is expected to mark a real decline of about $20 \%$ on average during 2014.

Euro-zone crisis has shown its effects mainly in the service sector. Given that the export of travel services is the main driver of total exports of services, the decline in this component, which is estimated to have been due to the smaller number of visits by the diaspora, has influenced the decrease in export services in general.

Although the data for the half-year anniversary of the first evidence for a decline of $18 \%$ of service exports, consumption data show a greater influx of diaspora mainly during July and August. Thus, by the end of 2014, the export of services is expected to fall by about $7.0 \%$. While the slowdown in economic growth in the country is expected to affect the decrease in imports of services and as a result, for the year 2014 imports of services is expected to fall by $3.2 \%$.

\section{Fiscal Compliance Trends}

Kosovo has a serious commitment to the creation of conditions for doing business. Government and agency business, chambers of commerce, have worked to adapt the conditions for the normal exercise of economic activity towards the competitiveness and standards.

According to the World Bank report "Doing Business Report 2015"

Kosovo is ranked in 63rd for payment of tax by 189 countries

- 33 (number per year) payment

- 155 hours per year (improvement of 162)

- $15.4 \%$ total listed taxes (percentage of profit)

According to the International Monetary Fund in February 2014. The objectives set by the Economic

Development program (SECO) to a large extent been achieved.

- Over the past three years, largely TAK is transformed into a tax administration service-oriented, which is significantly more in line with accepted good practices internationally.

- TAK has developed a powerful system management performance, with annual Plans Risk Management

(PTRR) and annual planning process operations

- Management meeting can be considered to be an example of best practice in the region.

- Compared with other countries in Eastern Europe, there is no doubt that the tax administration in Kosovo

has developed an excellent management system of tax compliance.

Impact of new Fiscal Policy paket 2015 in development of buisinesses Consequences of the acts or omissions of the state, which actions have an impact on the growth of informal economy, state mechanism, or use the law to fight against this phenomenon are the factors that directly reflected in business development policy or stalemate. Influences the implementation or non-implementation of laws, the growth of the informal economy. On the other hand implies Fiscal policy measures, plans and projections of the state government in the 
area of tax and other taxes respectively while meeting means the level of performance of obligations to taxpayers according to the legislation of a country ie execution or failure to carry out these projections. denominator of tax mis respectively Realising fiscal policies approved by the state, produces the informal economy as a real phenomenon. This means that there are a multitude of factors that affect the level of tax compliance or noncompliance and the implementation of government policies in certain periods. This phenomenon, although it is affected has not been studied enough, even taking into account the contemporary economic trends. Interest in determining the factors informal economy and other illegal activities has greatly increased in recent years. According to the authors most famous associated with the informal economy (Loayza, 1996; Johnson, 2000; Feige and Ott 1999; Elias and Zinnes, 2000; Ott, 2002; Schneider and Enste, 2002; etc.), are known several major factor affect the growth of informal economic activities, such as: high tax burdens (higher taxes), higher social security charges, complex regulations and licensing state, bureaucratic barriers, weak banking system, high rates unemployment, weak legal system, etc..

Tax Compliance as a notion related to tax economic category which serves to fill a state budget that will be expressed in financial terms mainly as money or monetary measure has to do with the science of finance as a scientific discipline that studies the phenomena, relations and institutions related to the creation, collection, distribution, redistribution, spending and managing money in order to meet the general needs and the process of social reproduction.

Tax fulfillment element which shows that fiscal policy: fiscal policy can change the level of economic activity in the private sector, thereby changing the balance between resources and expenditures of funds in the economy as a whole.

Separate emphasis of this paper will be a reflection of fiscal policy in the development of businesses and the economy, especially in the informal economy Tax policy and the integration of Kosovo in the global environment. Global economic recovery is continuing despite the large uncertainties that are followed these developments. In the medium term, these uncertainties mainly related to global economic movements in an environment which is characterized by considerable public debt, and if emerging economies, contributing to global economic growth will continue with economic growth without being influenced by movements in countries with advanced economies. Unlike the previous year, where growth was strongest during the 2014 global economic growth is slowing down in developed countries and in developing countries. In light of these developments, the International Monetary Fund (IMF) has lowered growth forecasts for 2015 where developed countries are expected to grow by about $1.5 \%$ (from $2 \%$ that was forecast earlier) and $3.5 \%$ in developing economies by $5.0 \%$ were early predictions.

The main factors considered slowing economic growth in certain countries and globally, is estimated to be fiscal consolidation (cuts in government spending) and credit is still low financial sector to the real sector. This is fiscal consolidation in order to reduce budget deficits in Effects of global risk in transition countries 525 order to reduce public debt, the amount of which is jeopardizing the fiscal stability of certain countries, with special emphasis on the so-called peripheral countries of the euro area. Forecasts for the euro-zone economy improvement give positive signals for economic growth in Kosovo. Economic growth for the period 2013-2015 is expected to be around 5.2\%\%, while in 2015 this growth is expected to be $3.5 \%$

Economic growth during this period mainly provided to support the growth of private consumption, investment and export in general. Based on the analysis of medium-term macroeconomic environment and under current fiscal policy parameters (these parameters resulting from the policies formulated in accordance with the economy's long-term needs of Kosovo) was forecast budget revenue collection for 2015. Projections for the total value of revenue collection resulting from base scenario assumptions on macroeconomic trends.

\section{Taxes - rates and tax compliance}

This forecast is the starting point for determining the overall level of spending and, consequently, for the selection of priority projects financing budget among many requirements that reflect the needs of the economy. VAT tax rate was $16 \%$ to be raised in 2015 to $18 \%$ corporate profit tax rate was $20 \%$ max to be reduced in 2009 to $10 \%$. 


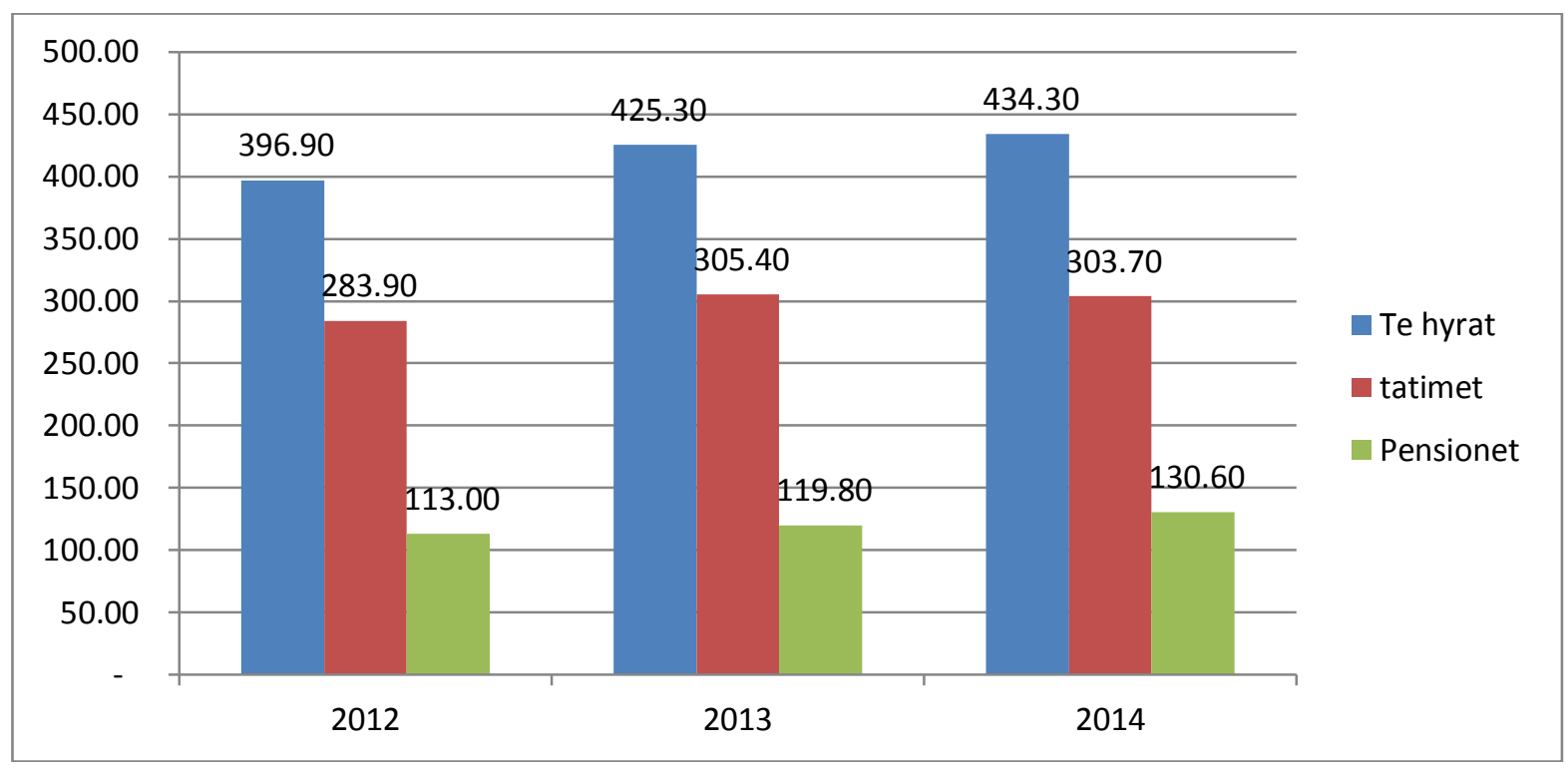

Other tax rates are grouped into three categories earnings realization. Annual income rates up to 950 Euro 0\%, with annual revenues up to 3000 Euro 4\%, those to Euro 5400 with $8 \%$ and above this $10 \%$ tax rate limit. Scenario building for 2013 envisages increasing the nominal value of the Gross Domestic Product (GDP) to $€$ 5.5 billion from $€ 5.09$ billion as it is the expected annual value for 2014 .

The main reason that supports this claim is to increase public and private investments that have lower coverage and replacing imports sharply against the trend component of the import of consumer goods. Also, the gradual growth of exports that have low import content is a contributing factor in this regard.

Data on this macroeconomic projections, the overall budget revenue collection during the year 2015 is projected to amount to $€ 1.65$ billion. Recovery of the gross revenues from taxes collected at customs is supposed to be at the level of $65 \%$, while gross tax revenue in the country are planned to be collected at the level of $€ 35 \%$. 1. Even in 2015, the highest share in revenue is expected to have value added tax payable in the country has, through corporate tax and income tax.

\section{Conclusions}

Conclusions Fiscal policies of various governments; loads on the one hand and tax incentives for businesses to work and created the largest income on the other hand are key factors that determine the level of competition for the global environment. The informal economy has an impact on the quality and level of public services, and unfair competition The larger firms informal economy, the greater the income that are not included in the state budget. The informal economy consists of unreported income from illegal work and undeclared sales. From the results obtained only a small number of variables involved are affecting the incidence and intensity of the informal economy. Proposals:

1. Equal fiscal policy and large-scale expansion, which enables a worthy competition and greater involvement of taxpayers in the state budget.

2. Mutual interest in partnership budgets, which means creating the climate for businesses to have a direct interest payment of taxes.

3. Improvement of the legislation in conformity with international conventions and membership of Kosovo in international institutions are the true path to include in the global market.

\section{Refrences}

[1] Sabahudin Komoni, Finance, Pristina.

Department of Treasury

[2] Tax Compliance SOST for Companiesin on enlarged European

[3] Annual Report of the Tax Administration of Kosovo in 2014 
[4] Diaspora and Migration Policies, Forum 2015, RIINVEST

[5] Monthly Statistical Bulletin, the Central Bank of the Republic of Kosovo, no. 166, June 2015

[6] Report of the Macroeconomic Developments, the Central Bank of the Republic of Kosovo, no. February 2015, Pristina

[7] Quarterly Economic Assessment no. 9, Quarter IV / 2014, the Central Bank of the Republic of Kosovo

[8] Study rEmiTTANCEs Kosovo, USAID, November 2010

[9] Financial Stability Report no. 7, Prishtina,

[10] Central Bank of the Republic of Kosov

[11] Study remittance's Kosovo, UNDP 2012

[12] https://ask.rks-gov.net/.../1073-studimi-mbi-remitencat

[13] http://www.riinvestinstitute.org/

[14] http://www.ks.undp.org/

[15] http://www.itg-rks.com/sq/Ballina

[16] http://www.evropaelire.org/content/article/24397436.html

[17] http://www.ekonomia-ks.com/?page=1,5,360384

[18] http://atkportal1/SitePages/Home.aspx 